\title{
Transport routes on technological lines and following problems
}

\author{
Jan Fiala ${ }^{1, *}$, Miroslav Lapka ${ }^{2}$, Jan Fiala jun. ${ }^{1}$, and Milan Mikolas ${ }^{2}$ \\ ${ }^{1}$ Brick factory of Srerboholy, 102 00, Praha-Sterboholy, Nedokoncena 163, Czech Republic \\ ${ }^{2}$ VSB-Technical University of Ostrava, 708 00, Ostrava, 17 listopadu, 2172/15, Czech Republic
}

\begin{abstract}
The article points out problems occurring on transport routes within the transfer of mind materials on technological lines for processing of raw materials, find possible solutions in increasing the lifetime of individual parts and in the area of maintenance and serviceability helps to Protect the health of employees of mining organizations and their suppliers. It conceives the problem of running a technology line as one big unit that combines innovative solutions with the use of modern materials. Increasing service life, reducing repair costs and reducing the frequency of repairs - especially those cyclically recurring. All of this helps to eliminate the number of accidents and this is why it protects the operator of the technology line. Ultimately maintenance costs are streamlined despite the relatively higher initial cost.
\end{abstract}

\section{Introduction}

Many operations of mining organizations deal with the issue of the transfer of treated raw materials between the individual stagesof the technological line for the processing of extraced mineral resources. The physical properties of the raw material are the main determining factor for the behaviour of the material at individual positions in the technological line and must be calculated in projects before the actual construction of the technological line.In most cases i tis not possible to provide sufficient information on the behaviour of a particular mineral in the individual phases of the raw material treatment, and therefore, after completion of the technological line, solutions are sought. Among the physical properties, the following are the key factors for the transport of materials along transport routes: the weight of individual pieces in a given fraction, abrasiveness and stickiness.

\section{Transport route}

The term "transport route" determines the places of the mined materials in the technological line from its entry to the final processing into individual products which are intended for dispatch. It is not only a belt conveyror, but a whole complex of individual technological equipment through which the material passes. The term "technology line"

*Corresponding author: j.fiala9@gmail.com 
is for the purposes of this Article, it shall be limited primarly to quarries where there is more difficulty in material transef than for example, in sand pits or other similar operations.

For our purpose we can divide traffic routes as follows:

- Stationary passive: chutes, transfer points, striking walls, flaps

- Stacionary active: vibrating feeders, belt feeders

- Moving: belt conveyors

- Other: ducts for extracting fine parts, filtering equipment

The technological line for processing raw materials is divided into 3 main sections:

- Primary section

- Secondary section

- Tertiary section

Each of these sections has different demands on the functioning of the technological line.

The primary section has 2 tasks. The first main task is to crush the extracted material into a factio up to $250 \mathrm{~mm}$, the second task is to separate fractions $0-22$ and $22-250$ from each other. This is done by demining screeners and primary crushers. In smaller quarries there is no primary crushers (mostly jaw) and one mulch separator. Larger quarries have a primary jaw crusher and a set of de-mining equipment (de-gratings + screeners). The assemblies of the primary jaw crusher and the primary cone crusher are also visible on some large quarries. In all cases, the main task is to prepare the extracted material for further processing in the secondary and tertiary sections. The main problem in the life of the individual parts on the primary section is due to the size of the input fraciton - weight parameters, sharpness of the aggregate and accompanying material $0-22$, which causes other problems with material stickiness in this section of the technological line. We have to differentiate the type of usable materials on individual transport routes. The material path of fraction $22-250$.

We cannot do this without quality hard rock shop windows with a thickness of about $20 \mathrm{~mm}$ supplemented with tooth plates type VSS60-80 mm. See Fig. 1 by combining these materials, we can maximize the service life of the transport route.

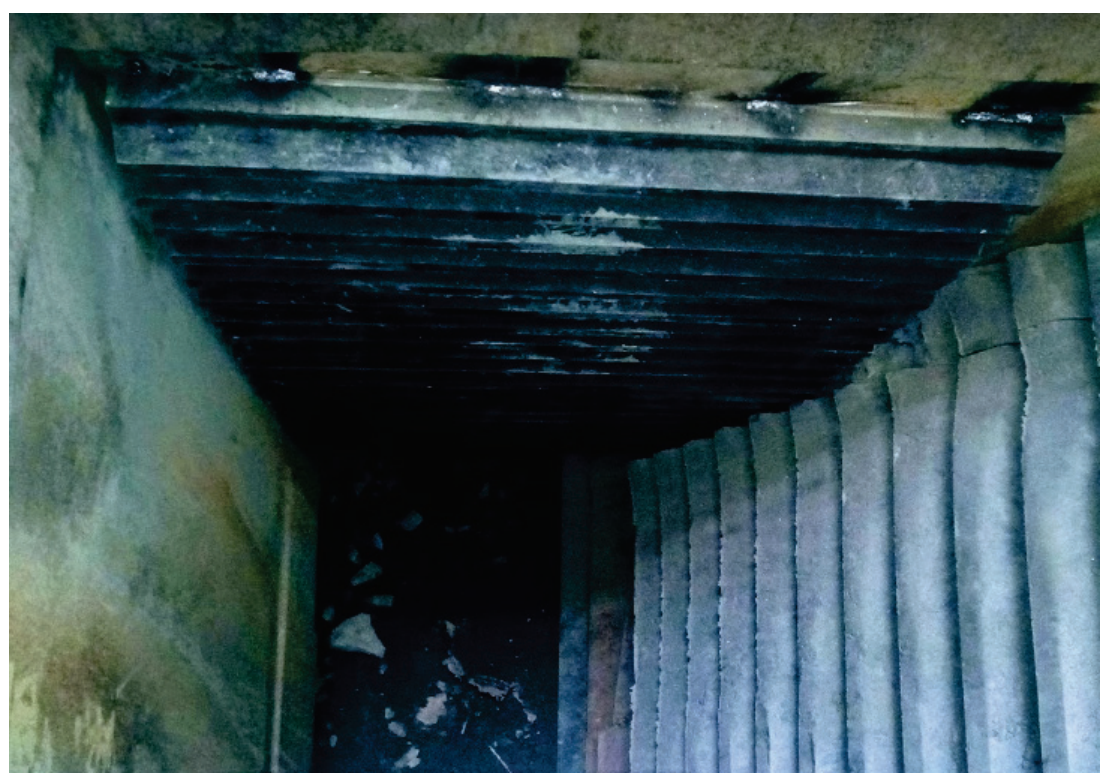

Fig. 1. Tooth plate VSSS60-80 mm (Source: WP systems s.r.o.). 
The minimum service life of the materials used must ensure trouble-free operation of the root for one year. (The period between large outages). To ensure belt conveyor clean leanness we recommend high-quality wiper technology in combination with the polyurethane in front wiper with a carbide-type main wiper technology in combination with the polyurethane front wiper with a carbide-type main wiper readily with torsional tensioning [1].

On the route of the materials of fraction $0-22$ it is nicessary to take into account increased problem of sticking the raw material. Gluing resistance is the most important in this section. Slips and dumps must be lined with materials other than hardox. Ideally considering the availability, price and features is the use of PE boards in an antistatic design, we work ideály with PE8000AST boards with a thickness of $10 \mathrm{~mm}$. It is an ideal material in terms of durability. Belt conveyors should be fitted with polyurethane conveyor belt wipers as much as possible in situ. Polyurethane has excellent self-cleaning properties [2].

\section{The secondary and tertiary sections}

To ensure the production of individual fractions for sale that is: production of finished products these are sections with a large number of conveyor belts, chutes, crushers, sorters, hoppers and due to an increased dustiness also with routes for extracting fines from the processed material Based on the information obtained, we can propose a solution to maximize the service life without changing the parameters for the quantity of transported material. Vibration feeders are the most vulnerable. Here due to the change in the antiabrasive lining material, shear friction can change between the new type of lining and the raw material Being transported thereby changing the speed of material transfer. This negatively affects the operation of the entire technological line. All activities and measures leading to an increase in service life must not negatively affect the production process in the production itself based on the fact that we have a fraction of $0-90$ In the secondary section and a fraction of $0-32$ on the tertiary section. It gives us quite a lot of choice in the materials that can be used to increase the service lifespan.

Stationary passive parts of the conveying route (chutes, transfer dumps, baffles, dampers): usable almost all steel rubber, polyurethane antiabrasive materials, necessiry of thorough selection, in case of poor choice the advantage becomes a strong disadvantage. Example: Figure 2 - polyurethane lining of the transfer point.

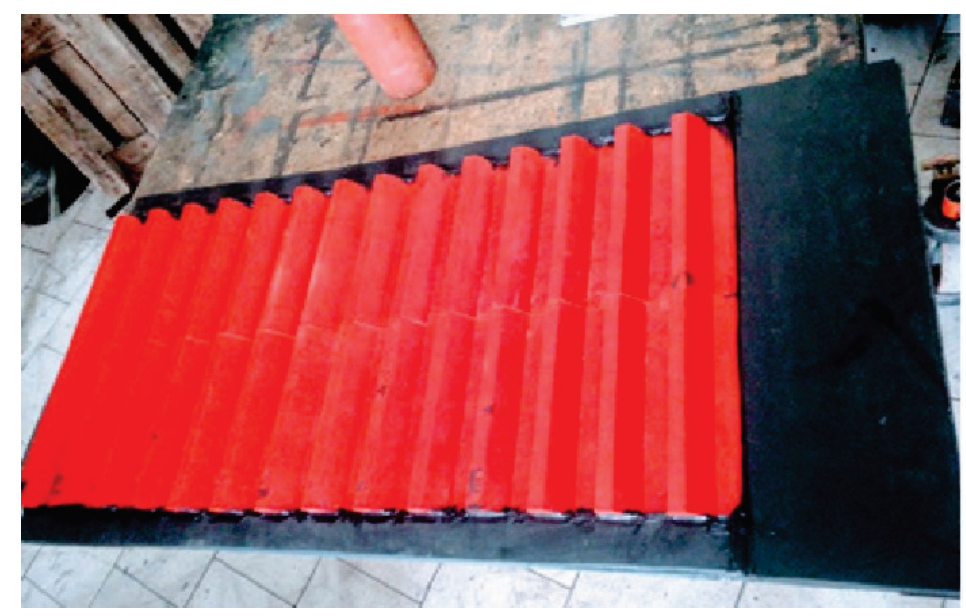

Fig. 2. PU tooth plate (Source: WP systems s.r.o.). 
Stationary active parts of the transport route (vibrátory feeders, belt feeders): usable hardox lining or rubber anti-abrasive lining, depending on the specific operating conditions. Example No. 3: rubber anti-abrasive lining of vibrating feeders. [3]

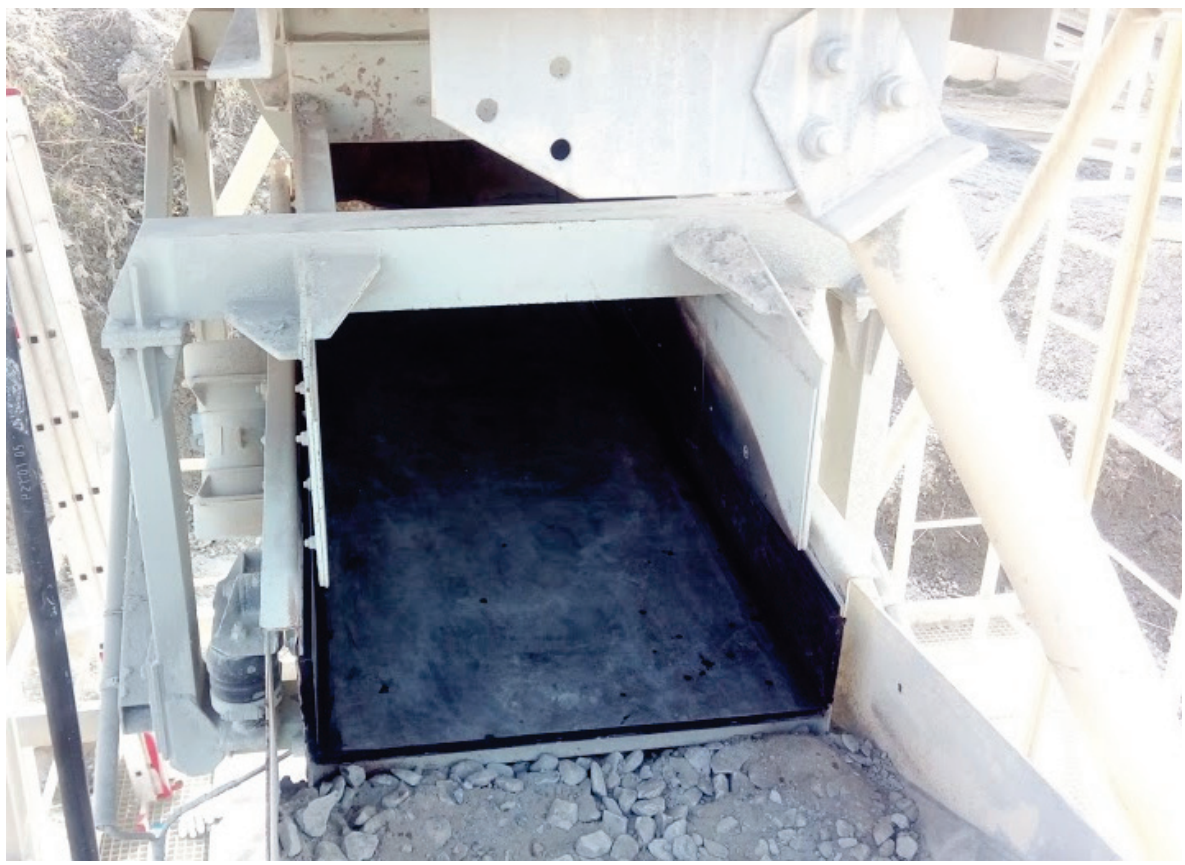

Fig. 3. Rubber lining gLB 60/CN 10mm (Source: WP systems s.r.o.).

Moving parts of the conveyor line (belt conveyors): in terms of mass transfer by means of a belt conveyor, we will mainly deal with the service life of the conveyor belt, Which is most suspectible to damage-choice of quality wiping technology. Rubber for lateral guidance, regular inspection of conveyor rollers, use of impact areas in places of Off impact of transported material example no. 4 impact area no. 5 wiping technique + slip lining PE 1000/10.

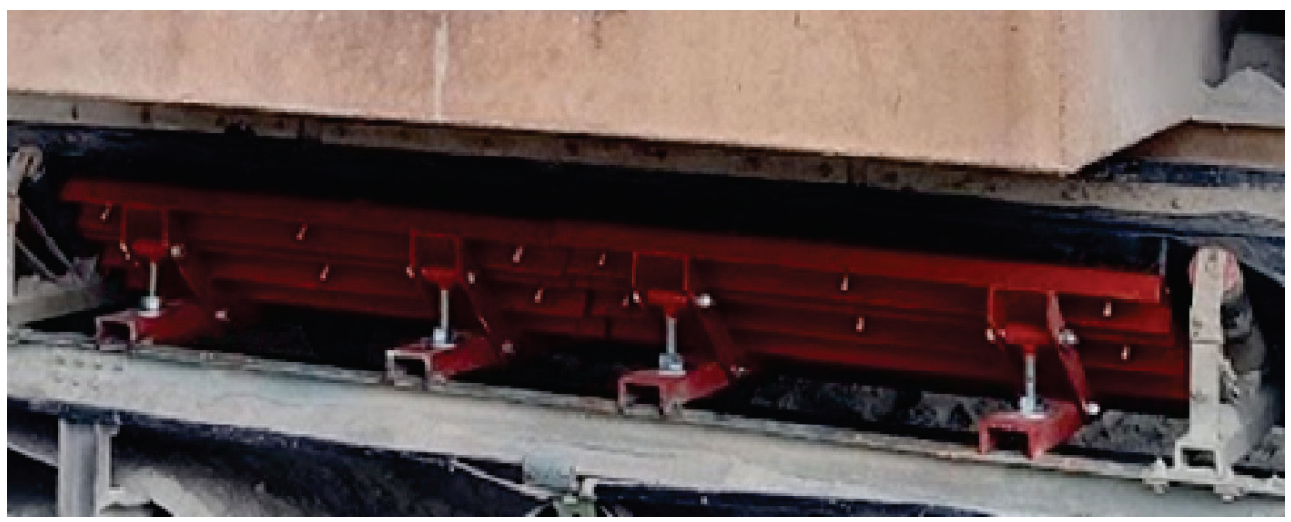

Fig. 4. DPL800/7 (Source: WP systems s.r.o.).

Other transport routes (piping for exhausting of fine parts filtration equipment): one of the most stressed places in terms of abrasion. The pipe is manufactured in class II. and II., increased durability ensures internal lining, usable are anti-abrasive rubbers and smooth 
polyurethanes. Example No.6: combination of rubber and polyurethane lining, Figure No. 7: rubberizing the internal parts of the filter station [4].

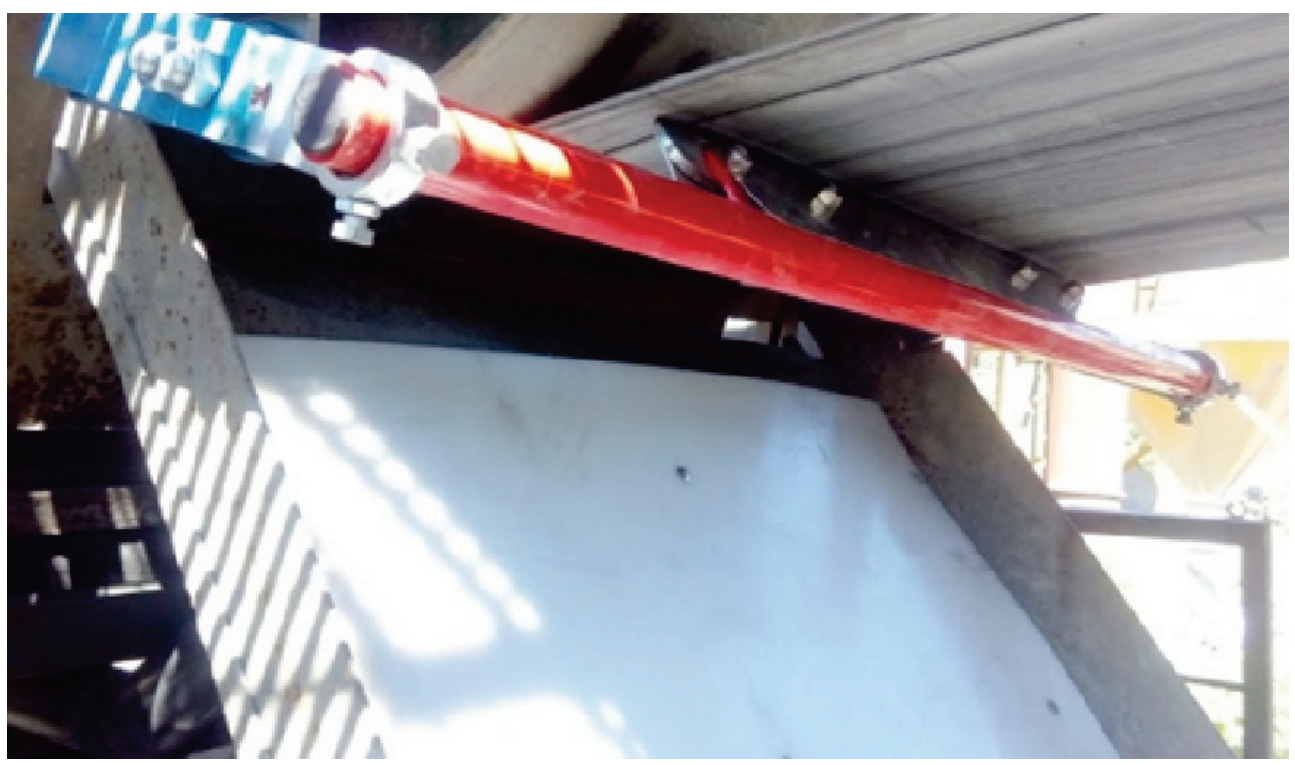

Fig. 5. Wiping technique (Source: WP systems s.r.o.).

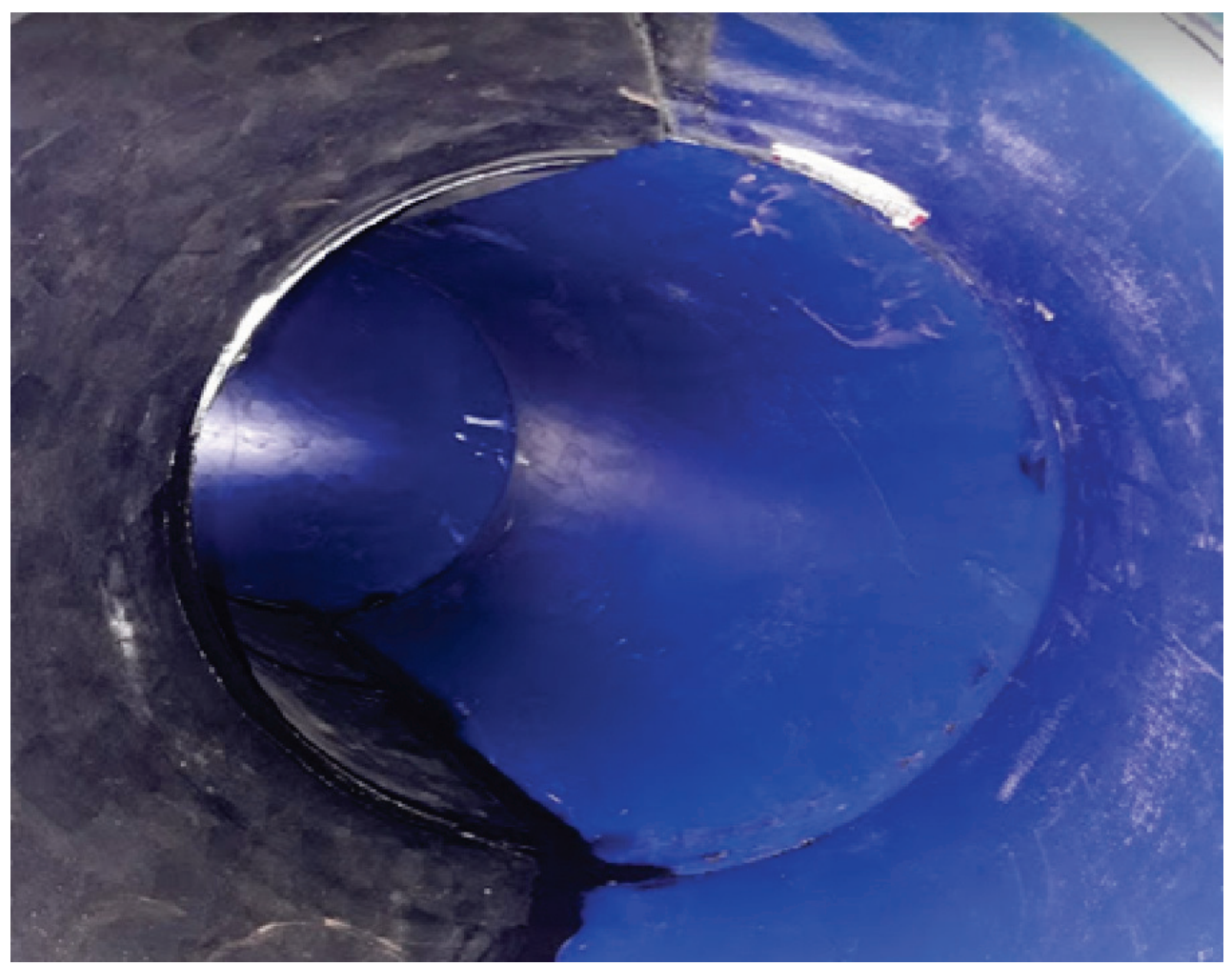

Fig. 6. Pipe unloading (Source: WP systems s.r.o.). 


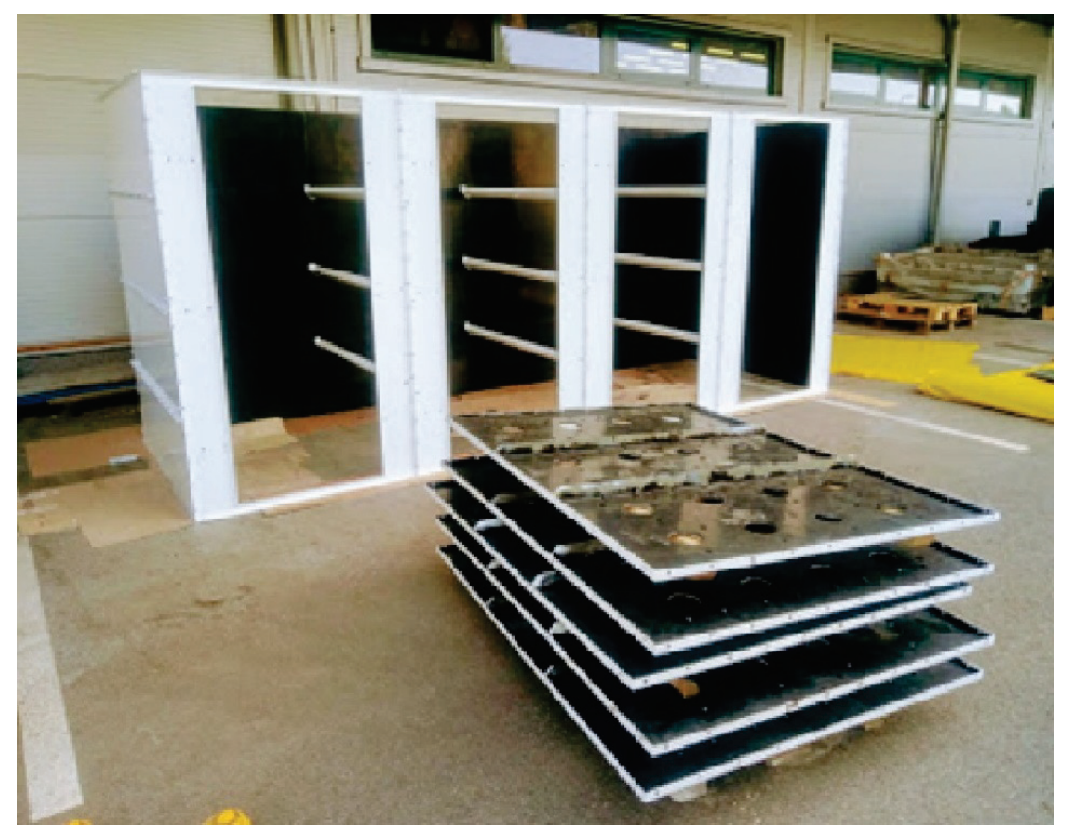

Fig. 7. Rubberizing of filters (source: WP systems s.r.o.).

\section{Conclusion}

This article shows several possibilities how to increase the lifetime of individual technological equipment intended for mineral processing. Based on information about the physical properties of the processed raw material in combination with the use of modern materials, it is possible to gradually mobdernize the already operational technological lines or to purposefully plan the reconstruction.

\section{References}

1. V. Kryl, E. Frohlich, Jan Sixta, Efface mountain action and recultivation, VŠB Ostrava, The Czech Republic

2. J. Grygárek, Václav Kryl, Systems development work deposits, VŠB Ostrava, The Czech Republic, 2000

3. K. Jeřábek, František Helebrant, Josef Jurman, Věra Voštová, Machines for terreous work. Road machines, The Czech Republic, 1996

4. M. Slivanský, Geomechanics, VŠDS, The Czech Republic, 1993 